\title{
Transfer of ownership notice
}

\section{Dear Reader,}

Recently, publishing houses Taylor \& Francis and IOS Press agreed that as of 2010 the publication of the journal Main Group Chemistry will be transferred to IOS Press BV, Amsterdam, the Netherlands.

\begin{abstract}
About IOS Press
Commencing its publishing activities in 1987, IOS Press (www.iospress.nl) serves the information needs of scientific and medical communities worldwide. IOS Press (co-) publishes over 100 international journals and about 130 book titles each year, on subjects ranging from computer sciences and mathematics to medicine and the natural sciences.
\end{abstract}

IOS Press continues its rapid growth, embracing new technologies for the timely dissemination of information. All journals are available electronically through iospress.metapress.com and an e-book platform, booksonline.iospress.com, was launched in 2005.

Headquartered in Amsterdam with satellite offices in the USA, Germany, India and China, IOS Press has established several strategic co-publishing initiatives. Notable acquisitions included Delft University Press in 2005 and Millpress Science Publishers in 2008.

It is IOS Press' goal to provide a high level of service and quality and wherever possible will seek for opportunities to further improve the journal in the coming years.

\section{IOS Press}

Nieuwe Hemweg 6b

1013 BG Amsterdam

The Netherlands

Tel.: +31 (0)206883355

Email: info@iospress.nl

www.iospress.nl 